\title{
Health Equity Column: Addressing Health and Racial Equity Requires Continuous Training
}

Jenné Johns, MPH



As a follow up to my inaugural article, Preemie Parent Perspective: Addressing Health Equity and Cultural Competency in the NICU. I want to introduce the Health Equity Column. The views and opinions expressed in this column are my own, as both an African American Micropreemie Mom, and National Senior Health Equity Leader. I welcome the readers of Neonatology Today to journey with me as we take a deeper look into health and racial equity issues plaguing our society and impacting Black NICU and Preemie families. In this months' column, we will examine the important role of continuous health and racial equity training for the neonatal and perinatal medical community.

Over the last few months' I have silently and emotionally witnessed the impact of two global pandemics: COVID-19 and its associated health, social, economic and political disparities, and the civil unrest of racism and police brutality in the United States. The surge of lives lost due to both pandemics requires us as a nation to address the value we place on each and every human life from a health, safety, and racial justice lens.

\section{"As the pandemic ramps down and stay-at- home orders expire, continued federal relief may be forthcoming. Access and support for pediatric care must be included."}

Historically in the United States, health and racial disparities were examined and addressed as intellectual, theoretical, quality improvement, and research exercises. These efforts yielded a plethora of government and philanthropic sponsored research grants, scholarly journal articles, intellectually agreed-upon theoretical frameworks. At best, it produced a few evidence-based clinical guidelines and best practices connecting quality improvement and health disparities. However, if we examine overall health and healthcare outcomes in premature birth rates and the survival rates of Black mothers and infants pre, during, and post-delivery, and the treatment of these families in the United States, these early exercises do not match the desired equitable health outcomes.

Recently, we have seen a wave of institutions committing to making large financial investments in the Black Lives Matters Global Movement with some designations to the Black Maternal Health Movement. Even though I believe this is a step in the right direction, our Black mothers and infants deserve more. In order for the financial commitments to match the much-needed health outcomes we desire including equitable maternal health outcomes, reduction in premature birth rates among Black infants, and drastic improvements in the survival rates of Black mothers and in- fants); it is equally imperative for our healthcare systems and its professionals to commit to continuous health and racial equity education and training that includes addressing the role of implicit bias when delivering care.

\section{"Despite healthcare institutions being encouraged to complete annual cultural competency training as recommended in the National Culturally and Linguistically Appropriate Services (CLAS) Standards, it is only a start for the general healthcare community."}

Despite healthcare institutions being encouraged to complete annual cultural competency training as recommended in the $\mathrm{Na}$ tional Culturally and Linguistically Appropriate Services (CLAS) Standards, it is only a start for the general healthcare community. CLAS Standard \# 4 is to: "Educate and train governance, leadership, and workforce in culturally and linguistically appropriate policies and practices on an ongoing basis." If this education and training CLAS provision is not monitored and recorded on a routine basis by healthcare institutions or regulatory and accreditation bodies, we will miss the opportunity to hold ourselves accountable as a healthcare community to deliver the high quality and equitable care, that is imperative for the neonatal and perinatal medical community. I believe it is time to pair annual CLAS training with continuous and routine Health and Racial Equity Training. This pairing is where we begin to see our commitment to training and organizational change match the equitable delivery of care for Black NICU and Preemie families.

As referenced in the June edition of Neonatology Today, Once Upon A Preemie Academy is a first of its kind to offer a virtual training program focused on health and racial equity training for all NICU and Preemie professionals. In order for this training program to support the education and training needs of the neonatal and perinatal medical community, we must collectively expand our health and racial equity journey together. We are seeking your help by:

1. Visiting our website and joining the listserv for important registration updates

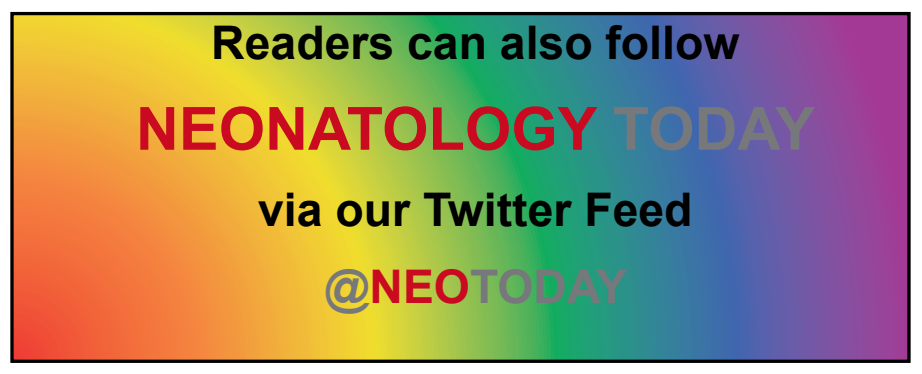


2. Increasing awareness about this training program with the NICU/Preemie Professional Community

3. Advocating for continuous health and racial equity training within your own institution

4. Consider sponsoring members of your team to attend our training program- see sponsorship prospectus on the adjoining page

5. Share your challenges, solutions, and success stories with us as we welcome your experiences to inform our training content.

We are all in this together, and together we will take a stand against racial disparities in the neonatal and perinatal communities.

For more information about the Once Upon A Preemie Academy, please visit: https://onceuponapreemieac.wixsite.com/website

Disclosure: The author has no disclosures.

NT
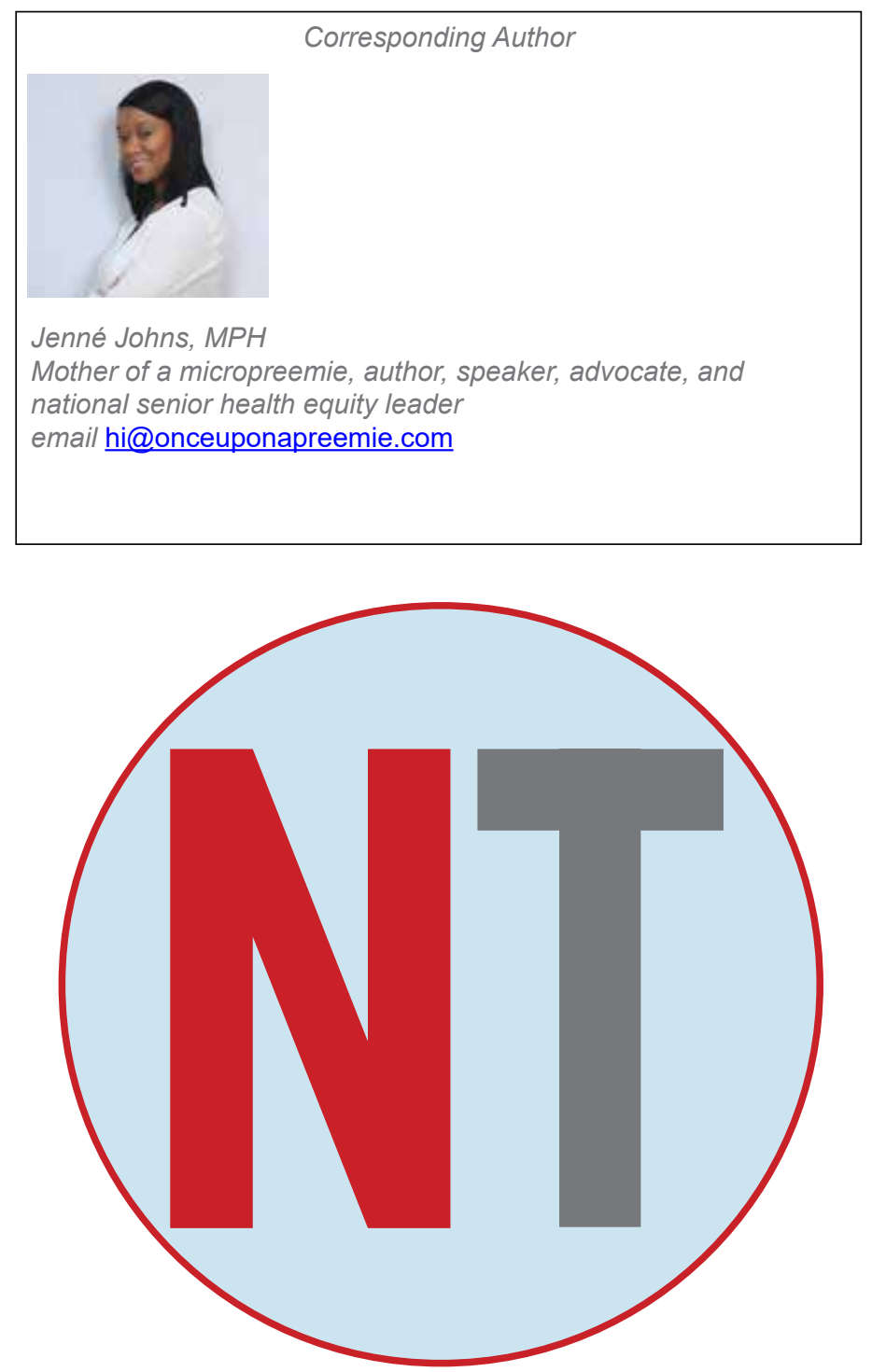

\section{Respiratory Syncytial Virus: How you can advocate for babies this RSV season}

Track national data and trends at the CDC's website

whw.cdc.gov/rsv

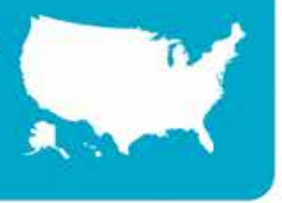

Identify babies at greatest risk



including those with CLD, BPD, CF, and heart conditions

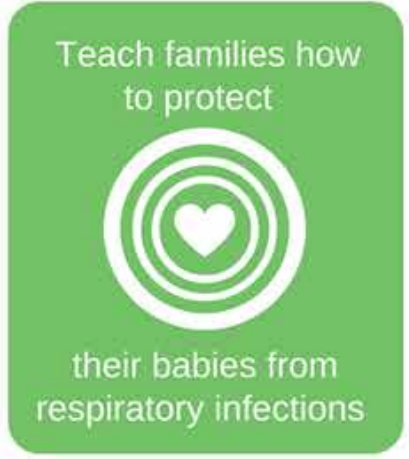

Advocate for insurance coverage for palivizumab prophylaxis so more babies can be protected *



Use your best clinical judgement

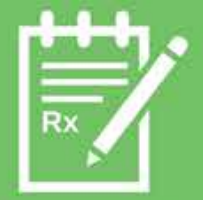

when prescribing RSV prophylaxis
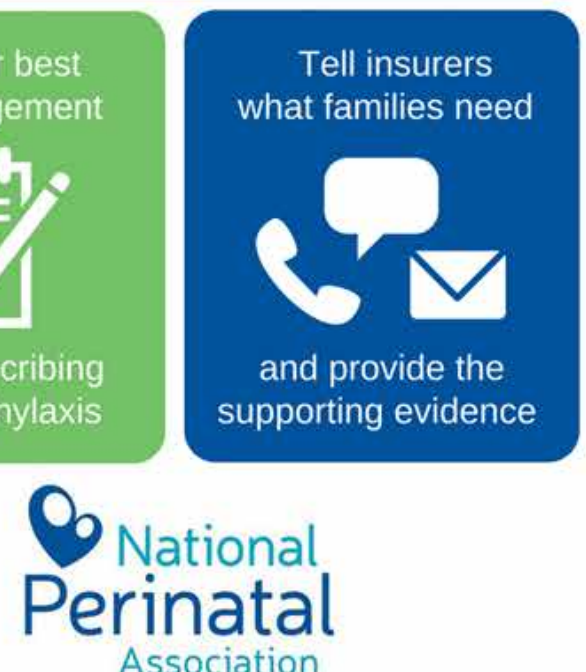

'See the NPA's evidence-based guidelines at www.nationalperinatal.org/rsv 